\title{
Design of three-dimensional cartographical didactic materials for Physical Geography teaching
}

\author{
Luis M. Tanarro, Jose Úbeda, Nuria de Andrés, José M. Fernández-Fernández, Javier \\ de Marcos, Diana Ovaco, Jesús García, David Palacios \\ Department of Geography, Universidad Complutense de Madrid, Spain.
}

\begin{abstract}
Three-dimensional cartographic resources are an important tool in the teaching of Physical Geography and other Earth Sciences. They are also able to help the students to reach a better understanding of the natural landscape. The objective of this work is to design appropriate $3 D$ didactic resources to facilitate the teaching of the landforms in the Higher Education context. These didactic materials have been prepared by using Geographic Information Technologies (GIT). These graphical materials have been created with specific GIT tools, but they can be used by teachers and students with standardized sotfware (Google Earth, Adobe Acrobat Reader or image viewers). Specifically, files with topographical and geological information have been prepared to work with Google Earth. The digital elevation models (DEM) can be viewed in three-dimensional files in 3D PDF format. This work also proposes the creation of photo-realistic images with thematic information draped with the DEM in isometric perspective. Finally, 3D models have been made from the application of photogrammetric techniques so that can be seen in stereoscopic mode as an alternative to the traditional techniques. In conclusion, all these $3 D$ didactic materials proposed in this work showed a great potential as complementary resources in the teaching and learning of Physical Geography and other Earth Sciences.
\end{abstract}

Keywords: $3 D$ Educational Resources; Physical Geography; 3D Cartographic Visualization; Photo 3D; 3D pdf; Google Earh. 


\section{Introduction}

Traditionally, teachers in Physical Geography and Earth Sciences education in general have used topographic maps that represent the relief by means of the so-called contour lines and spot heights. However, this didactic tool can make it difficult to understand the third dimension in the landscape representation. Instead, Geographical Information Technologies (GIT) facilitate learning through 3D visualization of the landscape, and it is an aid tool for those students that have a less developed 3D spatial perception (McCaffrey et al., 2003). For this reason, the three-dimensional cartographical or mapping resources can aid the teaching of the landforms (Anthamatten \& Ziegler, 2006). Commonly, the first step to show the landforms in three dimensions was the use of block diagrams often used in geomorphology handbooks (Proctor, 1963; Martínez de Pisón \& Castañón, 2006). At present, GIT have allowed the rapid generation of digital elevation models (DEM), through the Geographical Information Systems (GIS) and Computer Aided Design (CAD) software. These innovations have meant a new way of teaching geomorphology (Fisher, 1989; Allen, 2008). Also, the development of the GIT has provided automatic and more sophisticated methods for the graphic representation of the terrain, which allows to get a more realistic 3D geo-visualization. Moreover, it is also possible to drape various thematic layers to the DEM and apply different rendering techniques to obtain photorealistic scenes (Priestnall, 2009; Dübel \& Schumann, 2017). Since the emergence of Google Earth (GE) at the beginning of the 21st century, this tool has been one of the most used in the teaching of geography and geology (Patterson, 2007; Sanchez, 2009, Demirci et al., 2013; Hsu et al., 2017). In fact, students can visualize in GE different spatial information in a threedimensional way, and even elaborate topographical profiles easily (Hsu et al., 2017). On the other hand, the recent development of the Structure from Motion (SfM) photogrammetry is allowing to obtain 3D models of the landscape surface (Smith et al., 2015). The cartographical products generated in these programs can be exported to the commonly used Portable Document File (PDF) format with 3D content (*pdf 3D files). This widely used file allows the graphic representation of 3D data and its visualization with the commonly used Adobe Acrobat Reader. The interface of this program has several 3D tools that allow to the user (i.e., the teacher or the student) to interactively move, rotate, scale, measure and illuminate the 3D model in different modes (Mañana-Borrazás, 2014). Also, photogrammetry software offer generating stereo images, very useful for students to get a realistic three-dimensional (3D) visualization. The objective of this paper is to show the didactic potential of the 3D resources, which facilitate the teaching of geography, and above all, geomorphology. Although these materials necessarily have to be generated using GIT methods, the results can be exported to easy-to-use programs. 


\section{Materials and methods}

In this work, we have used different GIT tools to prepare and design different examples of 3D teaching resources. These 3D cartographic materials have been prepared by teachers and students of the Master in Geographic Information Technologies of the Complutense University of Madrid (Spain). From these GIT tools, the materials have been homogenized and exported to formats that can be opened in commonly used programs (GE, Adobe Acrobat Reader 3D, 2D and 3D image viewers), so that students can work easily with them. The elaborated 3D materials can be classified into 4 types of files:

\subsection{Google Earth files}

Topographic and geological maps at 1:50,000 scale are the materials prepared with GIT to create different $3 \mathrm{D}$ mapping products. The information contained in both types of maps is very dense, making it difficult to read and interpret. The Bentley MicroStation CAD platform has been used to simplify and prepare this information, and organize it in levels or layers (e.g. contour lines, spot heights, stream network, lithological units, tectonic symbols amongst others). Therefore, when exporting the CAD file to GE's native extension (*kml or $* \mathrm{kmz}$ ), this program recognizes the entire levels structure as it was designed on the CAD software.

\subsection{D PDF files}

The representation and analysis of the terrain through DEMs is an essential teaching resource in geography (Brown \& Olson, 2001). In this proposal, GIS and CAD programs have been used to generate DEMs, which have been subsequently exported as files in 3D *pdf format. The advantage of this extension is that it maintains all 3D information. Thus, this material offers unquestionable didactic possibilities since students can visualize the graphic representation of the landforms in their whole extent from different points of view.

\subsection{Images in different isometric views}

Generally, different thematic layers (e.g. geology, geomorphology, land uses, and even aerial photographs) can be overlapped on the 3D terrain model, and generate expressive isometric views. Usually, when using GIS programs with visualization purposes, the most common solution is to apply a transparency to the thematic variable that overlaps the DEM. However, in this work we propose to use alternatively the lighting and rendering techniques to generate photo-realistic 3D images (Dübel \& Schumann, 2017).

\subsection{D models}

The SfM photogrammetric technique, so called 3D photo-reconstruction, is a new tool with versatile teaching applications in multiple disciplines (Smith et al., 2015; Tomás et al., 
2016; Williams et al., 2016; Sautière et al., 2019). At present, it is possible to obtain 3D models and other cartographical products (point clouds, orthophotos and digital surface models) from the automated processing of a sequence of overlapping photographs, taken with drones or with simple commercial compact cameras.

\section{Results}

\subsection{Visualization of topographic and geological information in Google Earth}

GE offers a valuable didactic resource. Figure 1 shows the geological and topographical information of the surroundings of the Patones village (Central Spain) in GE, organized in levels (see table of contents on the left side). In this way, the student can interact in 3D, using the tools offered by the GE cartographic viewer: rotate and shift the view, change the exaggeration of the relief, activate or deactivate the levels, add transparency to the lithological units and create topographic profiles. These tools not only allow the simple visualization of information, but also its teaching use in a didactic way. As the information is organized in levels, students will have the possibility of activating or deactivating their display, facilitating the understanding of the interrelations between the different features of topographical and geological information.

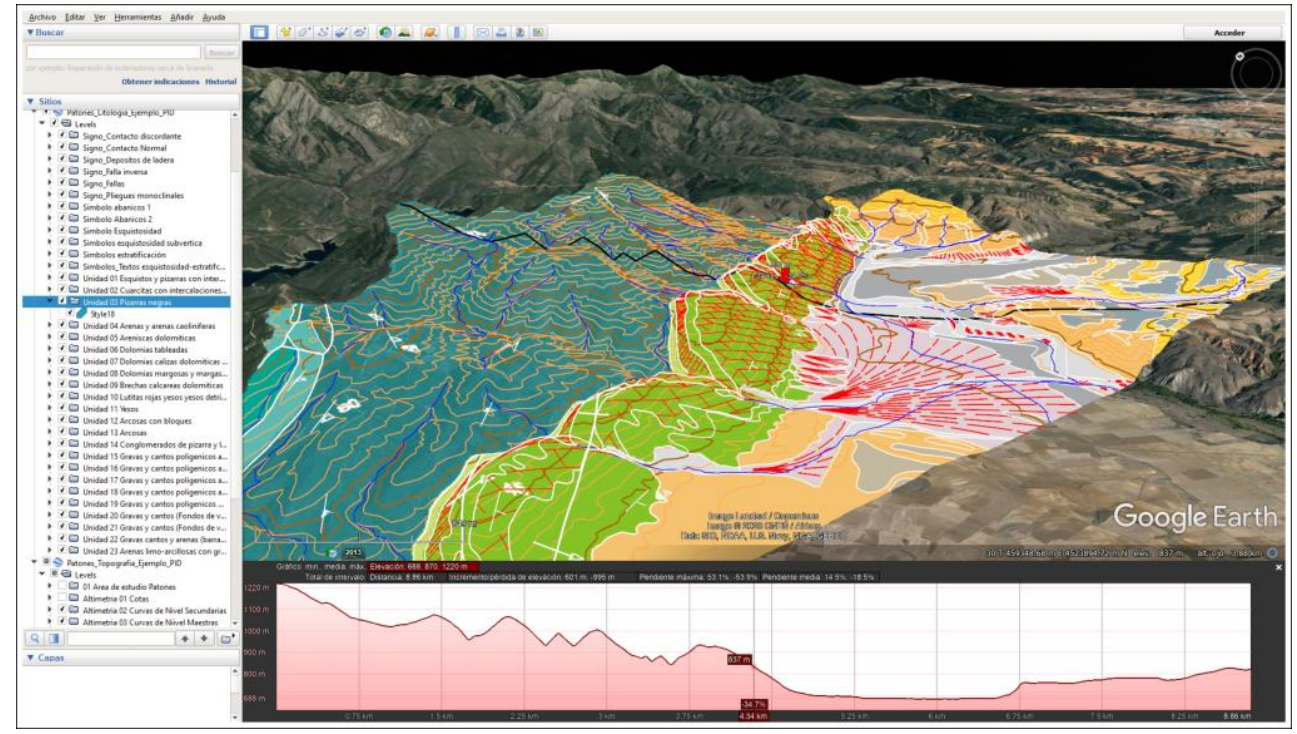

Figure 1. Example of didactic material prepared with CAD tools, and exported to be visualized and used in the Google Earth platform. Students could interact with the topographic profile (the black line in the $3 D$ view). The red arrow shows the location in the $3 D$ view of the geological map and its place in the profile. 
The students often have difficulty interpreting the 3D meaning of the contour lines as well as their relationship with the landforms (valleys, plains, divide, etc). Similarly, the visualization of the geology together with the contour lines and river network brings an easier learning of concepts such as dip and strike direction of the bed of sedimentary rocks, and observe the relationships between outcrop lithology and arrangement of the contour lines (e.g. V-rules of outcrops crossing valleys in geological mapping).

\subsection{Visualization of DEMs in $3 D$ PDF files}

Files in *pdf format with 3D content can be managed interactively with the 3D tools offered by Adobe Acrobat Reader. The 3D cartographic resource that has been prepared shows the DEM around of the Patones area (Fig. 2).

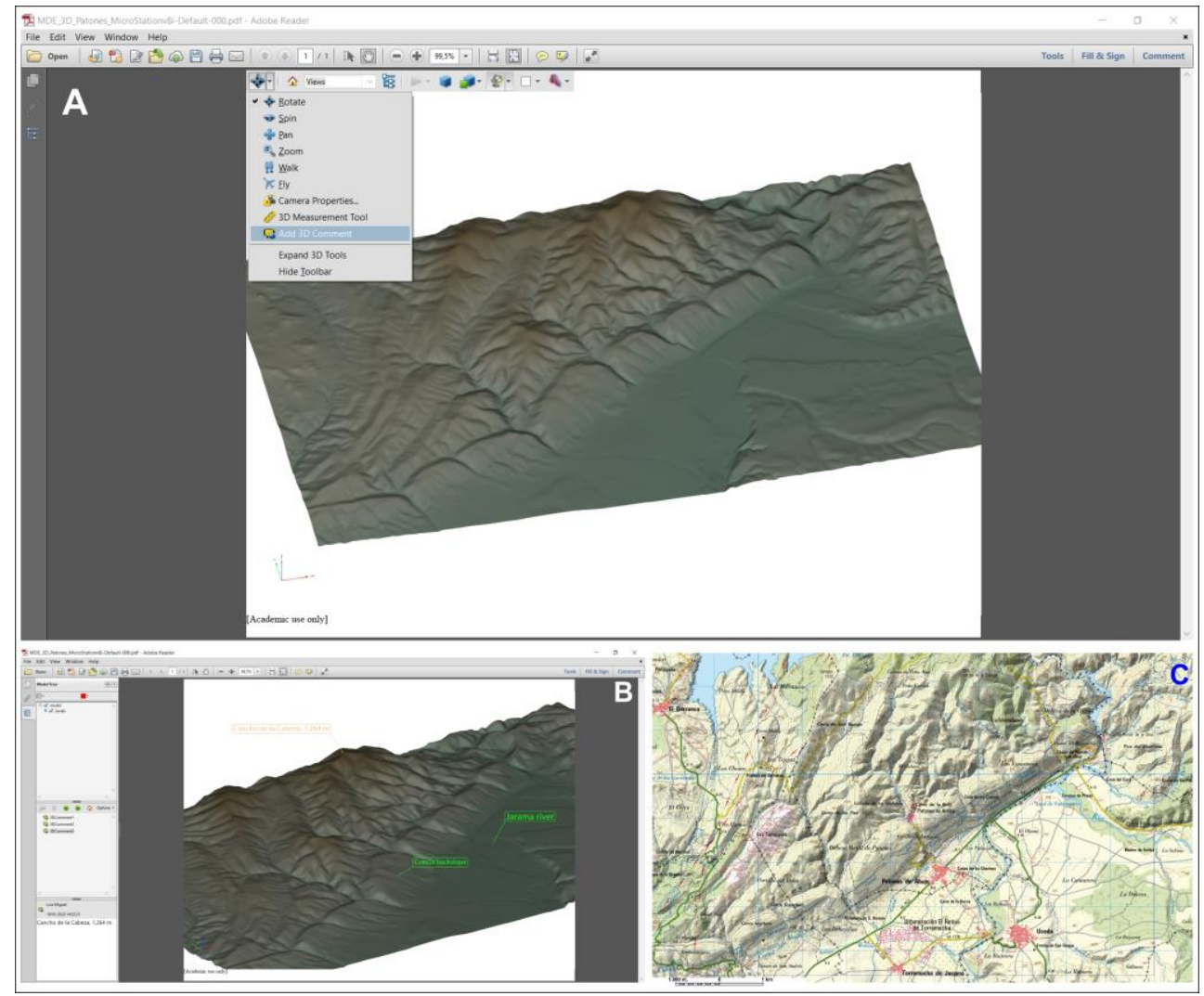

Figure 2. DEM prepared as a didactic material with TIG tools, and exported to visualize in the Adobe Acrobat Reader program (A). Example of comments added to the DEM (B) and topographic map of the study site $(C)$.

The students could apply different lighting styles and rendering modes (transparent, solid, illustration, shaded, wireframe) to display the $3 \mathrm{D}$ model. Therefore, this tools allow to visualize the model from different points of view, favoring the understanding of some basic 
geographic concepts (e.g. aspect, slope, etc.). In addition, students can work simultaneously with the topographic map and the DEM in order to locate and identify geographic features on the DEM, and also perform different types of measures or even add comments, indicating the location of geographical sites or features (peaks, rivers, places name, towns, etc.) or the main landforms that they recognize in the model (Fig. 2B and C).

\subsection{Visualization of thematic layers draped to the DEM in isometric views}

Photorealistic 3D images are also a valuable teaching resource. Although it is a "static" 3D scene (Allen, 2008), the teacher can create these images that facilitate the teaching of the landforms. For example, the isometric 3D scene of Figure 3 allow the teacher to explain how the relief is formed in relation to various variables: the topography (represented by the DEM), the stream network, the lithology and the tectonic structure.

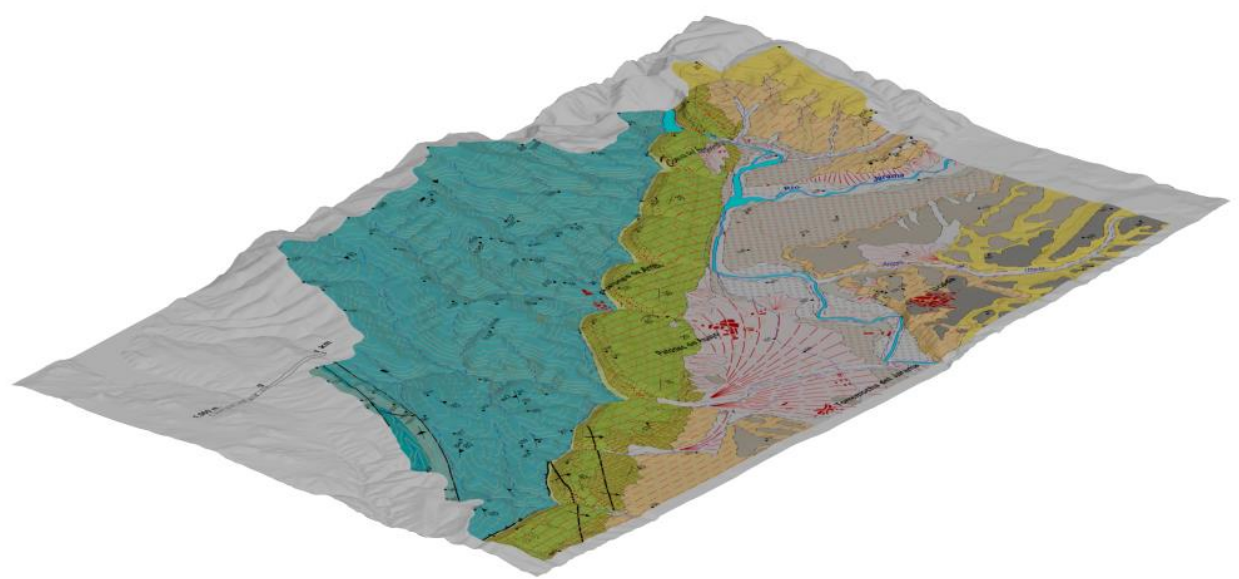

Figure 3. Photo-realistic 3D rendered image showing the lithology and tectonic structure draped on DEM.

\subsection{Detailed visualization and interpretation of the landforms with dynamic $3 D$ models}

As example, we have generated a 3D model of a small quarry with the use of the 3D photoreconstruction technique, using Bentley ContextCapture sofware. From a didactic point of view, this type of resource offers many possibilities in the teaching of physical geography and geology. In the example of the Fig. 4A, students could, among other activities, recognize the type of rocks, measure the thickness of the strata, recognize the competence and hardness of the rocks, and the relation between types and erosive processes, and even while visualizing the model in stereo mode with anaglyph 3D glasses (Fig. 4B). 


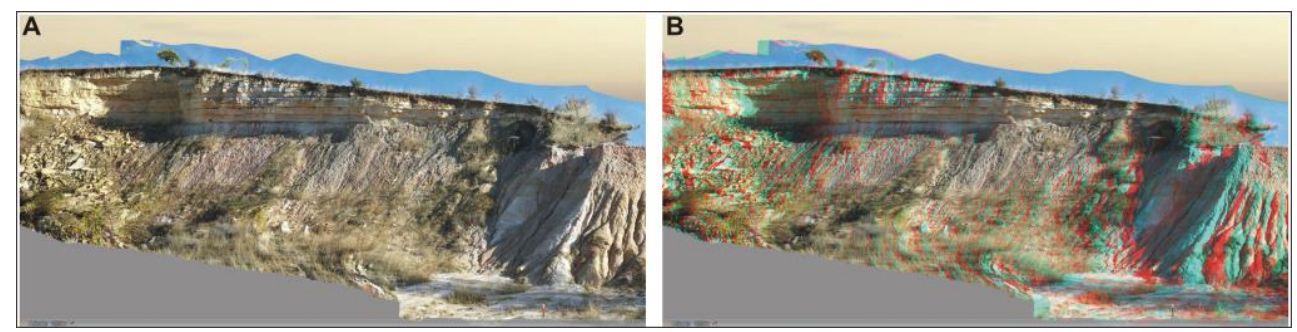

Figure 4. Example of a 3D model of a quarry. Normal isometric view (A) and stereo isometric view (B).

\section{Discussion and conclusions}

Topographical and geological maps, aerial and satellite images, block diagrams, digital elevation models and topographic profiles have been traditionally used for the teaching in geography and geology, as they help to reach a better understanding of the Earth's surface and the geomorphological processes (Allen, 2008). Its use is also essential when planning fieldwork activities (McCaffrey et al., 2003; Marra et al., 2017). Currently, these materials have been improved with the development of GIT, offering new opportunities in geography and geology education (Sanchez, 2009). From this perspective, the development and use of 3D cartographic resources will promote the understanding of the landscape for students.

The use of GE has shown its effectiveness as a didactic tool for the teaching of geography (Allen, 2008, Demirci et al., 2013). The students who learn with GE improve their abilities to read the topographic map, as well as to assimilate concepts of geomorphology (Hsu et al., 2017). In fact, the application of 3D geovisualization techniques has become a priority objective of researchers for scientific, educational and outreach purposes (Dübel \& Schumann, 2017). On the other hand, generating photorealistic 3D images could be an extraordinary recourse to explain a particular landform, the configuration and evolution of the relief or landscape or to acquire mapping skills (Hsu et al., 2017). The 3D representation and visualization of the terrain in novelty applications such as Adobe Acrobat Reader, or the creation of 3D models with SfM technique, with the possibility of generating stereoscopic images, opens up multiple possibilities in the teaching of geography or geology (Smith et al., 2015).

However, work with 3D cartographic materials would not be enough to achieve student learning, if the teacher does not propose its use with didactic objectives and activities. All in all, 3D cartographical materials are useful as complementary resources since they ease the teaching activities and improve student learning and understanding of the theoretical contents. The present work has demonstrated the pedagogical potential of elaborated 3D mapping materials. These resources have been implemented in the current academic course in the practical activities of the subject "Physical Geography" (Archaeology Degree), although they still have not been assessed in the class sessions. Thus, we will have available 
results in the near future to confirm a better understanding of the theoric contents by the students.

\section{Acknowledgments}

This work is part of the GeoFieldTIG project $\left(n^{\circ} 87\right.$ ), founded by the Complutense University of Madrid.

\section{References}

Allen, T.R. (2008). Digital terrain visualization and virtual globes for teaching geomorphology. Journal of Geography, 106:6, 253-266, doi: $10.1080 / 00221340701863766$.

Anthamatten, P. \& Ziegler, S.S. (2006). Teaching Geography with 3-D Visualization Technology. Journal of Geography, 105: 231-237; doi.org/10.1080/00221340608978692

Brown D. G.\& Olson, J. M. (2001). Integrated teaching of Geographic Information Science and Physical Geography through digital terrain analysis. Journal of Geography, 100:1, 4-13, doi: 10.1080/00221340108978412.

Demirci, A., Karaburun, A. \& Kilar, H. (2013). Using Google Earth as an educational tool in secondary school geography lessons. International Research in Geographical and Environmental Education, 22:4, 277-290, DOI: 10.1080/10382046.2013.846700.

Dübel, S. \& Schumann, H. (2017). Visualization of features in 3D Terrain. ISPRS International Journal of Geo-Information, 6, 357; doi:10.3390/ijgi6110357.

Fisher, P.F. (1989). Geographical Information System software for teaching. Journal of Geography in Higher Education, 13:1, 69-80, doi: 10.1080/03098268908709059.

Hsu, H.P, Tsai, B.W. \& Chen, C.M. (2017). Teaching topographic map skills and geomorphology concepts with Google Earth in a one-computer classroom. Journal of Geography, doi: 10.1080/00221341.2017.1346138.

Mañana-Borrazás, P. (2014). Utilidades del pdf 3D. Instituto de Ciencias del Patrimonio, CSIC. http://hdl.handle.net/10261/63515.

Martínez de Pisón, E. \& Castañón Álvarez, J. C. (2006). Evolución del empleo de los bloques-diagrama en la representación gráfica del relieve. In: N. Ortega (Coord.). Imágenes del paisaje. Universidad Autónoma de Madrid, Madrid, 101-147 pp.

Marra, W.A., van de Grint, L., Alberti, K. \& Karssenberg, D. (2017). Using GIS in an Earth Sciences field course for quantitative exploration, data management and digital mapping. Journal of Geography in Higher Education, 41:2, 213-229, doi: 10.1080/03098265.2017.1291587.

McCaffrey, K., Holdsworth, R., Clegg, P., Jones, R. \& Wilson, R. (2003). Using digital mapping tools and 3-D visualisation to improve undergraduate fieldwork. Planet, 11:1, 34-37, doi: 10.11120/plan.2003.00110034. 
Patterson, T. C. (2007). Google Earth as a (Not Just) geography education tool. Journal of Geography, 106:4, 145-152, doi: 10.1080/00221340701678032.

Priestnall, G. (2009). Landscape visualization in fieldwork. Journal of Geography in Higher Education, 33:S1, S104-S112, doi: 10.1080/03098260903034020.

Proctor, N. (1963). Using Block Diagrams in teaching geography. Geography, 48(4): 393398. https://www.jstor.org/stable/40565713.

Sanchez, E. (2009). Innovative teaching/learning with geotechnologies in Secondary Education. 3 World Conference on Computers in Education, 65-74, doi: 10.1007/978-3642-03115-1_7.

Smith, M. W., Carrivick, J. L. \& Quincey, D. J. (2015). Structure from Motion Photogrammetry in Physical Geography. Progress in Physical Geography, 40(2): 247275, doi.org/10.1177/0309133315615805.

Sautière, P.E., Delbende, C., Deleplanque, B., Mikolajczyk, B. \& Vizioli, J. (2019). Photo 3D technology applied to e-Learning tools production for animal biology. 5th International Conference on Higher Education Advances (HEAd'19), 921-928. doi: http://dx.doi.org/10.4995/HEAd19.2019.9225.

Tomás, R., Riquelme, A., Cano, M. \& Abellán, A. (2016). Structure from Motion (SfM) una técnica fotogramétrica de bajo coste para la caracterización y monitoreo de macizos rocosos. Reconocimiento, tratamiento y mejora del terreno, $10^{\circ}$ Simposio Nacional de Ingeniería Geotécnica. La Coruña, 209-216.

Williams, R. D., Tooth; S. \& Gibson, M. (2016). The sky is the limit: reconstructing physical geography from an aerial perspective. Journal of Geography in Higher Education, doi: 10.1080/03098265.2016.1241986. 